\title{
The application of seismic reconstruction inversion in Daqing Changyuan oilfield development zone
}

\author{
Wang Long \\ Petro China Daqing Oilfield Company, Daqing 163000, China
}

Keywords: separation, channel, transition zone of the oilfields, Daqing Changyuan.

\begin{abstract}
Daqing Changhua oilfield has been into a period of determining, transition zone have been closely watched as the basis of potential areas, but the transition zone has a problem of the low degree of use, conventional reservoir interpretation method is difficult to satisfy the requirement of accuracy. In order to solve this problem, by using the method of reconstructing separation with micro electrode resistivity curve and microspheres, which to establish a set of suitable for the technical flow transition zone in the oil field of fluvial faces reservoir prediction. Development of $\mathrm{X}$ in Daqing oilfield as an example, through the processing method of dimension the absolute difference and the amplitude difference of homogenization, which implement the process of logging curve reconstruction in the study area, and through four key link of inversion, complete separation reconstruction inversion in the study area. Confirmed by drilling, based on the separation seismic reconstruction inversion to predict drilling coincidence rate is higher, combining with seismic attributes such as achievement, supplemented by core, well logging, mud logging data, and complete $\mathrm{S}$ main reservoir sedimentary unit sedimentary microfiches in the study area. Comprehensive studies have shown that, this method is high precision to predict river, can be used as an effective method for prediction of oilfield transition zone channel.
\end{abstract}

\section{Geological background}

X development transitional zone locates in XB oilfield, Daqing Changhua, Song Liao basin. The area of it is $19.97 \mathrm{~km}^{2}$. By the year of 2008 , we have finished the middle-shallow layer high-density 3D seismic data processing. The seismic bin is $10 \times 10$ and the seismic trace interval is $50 \mathrm{~m}$. The transitional zone is "west high, east low" slope structural belt.The average formation dip is $19^{\circ}$ and the average depth of oil-water interface is $1050 \mathrm{~m}$. The faults in this zone mainly are tensional normal faults that are developed ${ }^{[1]}$. The main fault strikes are NW and NNW direction. Up to now, there are 192 development wells that mainly locate in the west development zone of transitional zone.The transitional zone is blanked area where the formations develop well. Due to the deeper structure position, what under the S II of Soil layer is water layer. The reservoir condition of S I is bad that there is almost no oil in it.The oil-bearing formation mainly locates in several brunt sedimentary units.The lithology of the oil-bearing reservoir mainly are sandstone and fine sandstone.and the plane extends as peasecod.The sedimentary background is delta external front sedimentary environment.

\section{The implement method of reconstruction inversion method}

It will be meaningful for the oilfield development when the seismic reservoir prediction corrects to thin layer ${ }^{[2]}$. Therefore, reconstruction seismic inversion technology can realize high precision inter-well prediction.Good practice dictates that channel sand is the main oil-bearing reservoir.So,the research focuses on implementing the channel extension characteristics of transitional zone.The investigation indicates that the effective thickness of formation is the most intuitionistic presentation to reflect the channel sand.Usually,the effective thickness of channel sand is the positive rhythm combination of lithology that monolayer's thickness is greater than $1.8 \mathrm{~m}$. Hence the channel sand recognition described by transitional zone equals to the prediction of effective thickness.However the effective thickness relates closely to the amplitude difference of electric curve of microelectrode (RMN) and microspheres (RMG).For this reason, it is necessary to build up a curve that can reflect 
the effective thickness of reservoir to make it able to replace the acoustic curve to inverse in order to complete the prediction of channel in the transitional zone (Fig.1). The detailed process is as follows:

(1) The quantification to the curve of microeletrode and microspheres ${ }^{[3]}$. Because the logging curves of different years have different dimension that the calculation results have a strong impact on prediction accuracy.Therefore,it is necessary to make an attribute dimensional treatment to original logs.

$$
X_{i}^{(k)}=X_{i}^{(k)} / X_{i}
$$

(2) Let sequence of microelectrode curve:

$$
X_{0}=\left\{x_{0}(1), \ldots, x_{0}(n)\right\}
$$

The sequence of computed microspheres curve:

$$
X_{1}=\left\{x_{1}(1), \ldots, x_{1}(n)\right\}
$$
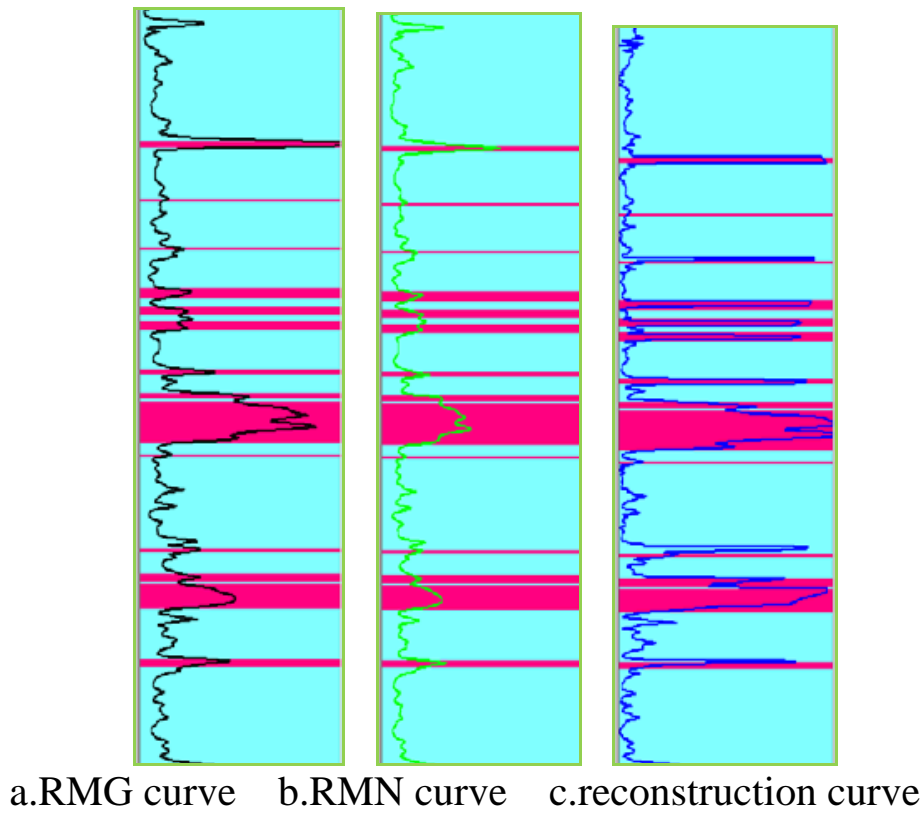

Fig. $1 \mathrm{X}$ development transitional zone amplitude difference curver reconstruction schematic diagram

(3) The absolute difference evaluation of the two sequences.The calculation formula of magnitude difference $\varepsilon^{(k)}$ is:

$$
\varepsilon^{(k)}=\left|\mathrm{X}_{0}^{(\mathrm{k})}-\mathrm{X}_{1}^{(\mathrm{k})}\right|
$$

(4)The homogenization treatment of amplitude difference.The channel scale and the difference of physical properties cause the amplitude defferences vary in size.Generally speaking,the channel scale in development zone is greater than in transitional zone. While the oversize amplitude difference $\varepsilon^{(k)}$ in seismic inversion calculation will reduct the thinner effective thickness.For this reason,we have to homogenize every amplitude difference $\varepsilon_{i}$ to improve the accuracy of the channel prediction in transitional zone as far as possible.

$$
\varepsilon_{i}=\frac{\left(\varepsilon_{\mathrm{std}}^{\max }-\varepsilon_{\mathrm{std}}^{\min }\right)\left(\varepsilon-\varepsilon_{\mathrm{i}}^{\min }\right)}{\varepsilon_{\mathrm{i}}^{\max }-\varepsilon_{\mathrm{i}}^{\min }}+\varepsilon_{\mathrm{std}}^{\min }
$$

\section{Effect evaluation}

\subsection{Inversion profile effect}

Inversion accuracy and reliability are a leading indicator to evaluate the inversion effect.Compared to original wave impedance, the effect of seismic reconstruction inversion has been 
improved obviously ${ }^{[3-4]}$. First of all, it has an excellent effect on seismic inversion resolution. Take connecting-well inversion profiles as example,the sand stones in development zone are well-developed that can be recognized 5 covers sand bodies in the longitudinal direction.Especially in both sides of reverse faults,the sand bodies are well-developed and each sand body spreads as parallel and sbuparallel;Secondly, we have to overcome the "modeling" effect in transitional non-well area,that it extends intrtmittently; Finally ${ }^{[5]}$,the accuracy of reconstruction inversion magnitude difference is higher.We can know from the statistics of affiliate wells and posterior wells in transitional zone that channel sand's average coincidence rate of affiliate wells is $88.0 \%$ while the latter is $77.0 \%$.Among them,the coincidence rate of SII8 sedimentary unit is the highest.The coincidence rate of affiliate wells is $88.9 \%$ while the latter is $83.3 \%$.

\subsection{Plane effect}

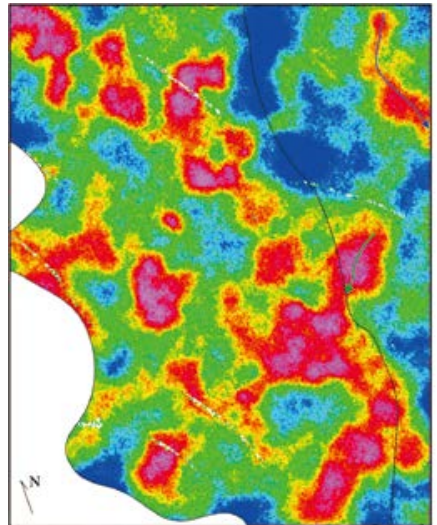

a. inversion along-layer slice

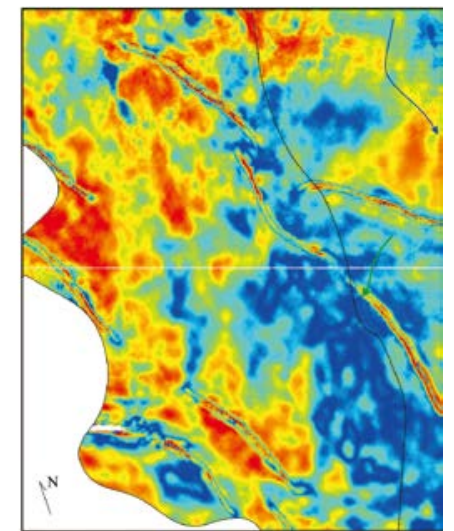

b. seismic along-layer attributes

Fig $2 \mathrm{X}$ development transitional zone SII1unit seismic along-layer result map

The seismic inversion amplitude slice accords well with the sedimentary unit amplitude slice.The seismic attributes can reflect the development condition of sand body ${ }^{[6]}$.The higher seismic inversion magnitude difference indicates the better developed sand stone ${ }^{[7]}$. We can see from the inversion that the sand bodies in structural high part of development zone are well-developed while the sand bodies in structural low part of east transitional zone are poor-developed.Take SII11 unit seismic inversion slice and seismic attributes as example(Fig 2a and Fig 2b),the seismic inversion show that middle and advanced amplitude dfference zone is the development zone of sand stone.If the correspondent seismic attribute is warm zone, it shows that it is development favorable area of sand stone.There are mainly two places of sand stone development zones in transitional non-well zone.The middle seismic inversion high value area extends as cuspate shape(green arrow part) that locates in the northeast work area(blue arrow part) where the correspondent seismic attribute is abnormal higher zone.Compared with channel drilling in development zone, it is predicted as channel development zone.

\section{Main cognitive}

We propose a method of using the amplitude difference seismic reconstruction inversion to predict the channels in transitional zone for the problem of prediction.We quantify the curves of microeletrode and microspheres and calculate the absolute difference evaluation of the two sequences.Then we get an amplitude reconstruction curve and homogenize every amplitude difference curve after reconstruction.By the key link of small-scale structure interpretation,structure modeling restraint original model, constraint sparse pulse deterministic inversion and well-seismic combined inversion by degree,we finished the seismic reconstruction inversion prediction of $\mathrm{X}$ development zone in transitional zone.Comprehensive study shows that using the amplitude difference seismic reconstruction inversion to predict the channels has a better effect.Other seismic inversion affiliate wells' accuracy is higher and the error of posterior wells is limited within 25\%.The practice shows that the amplitude difference reconstruction method are significant meaningful to predict the channels in oilfield transitional zone. 


\section{Reference}

[1] Chen Qinghua, Zeng Ming, Zhang Fengqi, et al. Identification of single channel in fluvial reservoir and its significance to the oilfield development[J]. PGRE, 2004, 11(3): 13-15.(in Chinese)

[2] Li Zhandong,Zhao Wei, Li Yang, et al, Feasibility study and application of development seismic inversion-a case study from northern Changyuan oilfield of Daqing area [J]. Oil\&Gas Geology, 2011, 54(32): 797-806. (in Chinese)

[3] Li Zhandong, Liu Yikun, Hai Dongming. Application of the Reservoir Feophysics Technology to LS Oilfield of Daqing Changyuan[J]. Geoscience, 2013, 27(3): 694-702. (in Chinese)

[4] Wang Qi, Li Hongmei. Application of development seismology to reservoir prediction of Lamadian oilfield in Daqing placanticline [J]. Oil\&Gas Geology 2012, 33(3): 490-496. (in Chinese)

[5]Li Zhandong, Li Ji, Li Yang,et al.Structure modeling-constrained seismic inversion technology-a case study from Nanba area in Saertu oilfield, Daqing [J]. Oil\&Gas Geology, 2013, 34(3): 400-406. (in Chinese)

[6]Jiang Lian, Zeng Yi, Wen Xiaotao, etc. Description of sand body thickness based on seismic facies analysis [J], Fault-block Oil\&Gas Field, 2011, 18(3): 273-276. (in Chinese)

[7]Jin Li. Application of Evaluation of Gary Correlation to Analysis of the Groundwater Quality in the Mining Area [J], Fault-Block Oil \& Gas Field, 2012, 19(5): 600-603. (in Chinese) 